\title{
Author Correction: Hydrophobic pore gates regulate ion permeation in polycystic kidney disease 2 and $2 \mathrm{~L} 1$ channels
}

Wang Zheng ${ }^{1,2}$, Xiaoyong Yang ${ }^{3}$, Ruikun $\mathrm{Hu}^{4}$, Ruiqi Cai ${ }^{2}$, Laura Hofmann ${ }^{5}$, Zhifei Wang ${ }^{6}$, Qiaolin $\mathrm{Hu}^{2}$, Xiong Liu ${ }^{2}$, David Bulkley ${ }^{7}$, Yong Yu ${ }^{6}$, Jingfeng Tang ${ }^{1}$, Veit Flockerzi ${ }^{5}$, Ying Cao ${ }^{4}$, Erhu Cao ${ }^{3}$ \& Xing-Zhen Chen ${ }^{1,2}$

Correction to: Nature Communications https://doi.org/10.1038/s41467-018-04586-x, published online 13 June 2018

The original version of this Article contained an error in the spelling of the author David Bulkley, which was incorrectly given as David Bulkey. This has now been corrected in both the PDF and HTML versions of the Article.

Published online: 26 March 2019

\begin{abstract}
(c) (i) Open Access This article is licensed under a Creative Commons Attribution 4.0 International License, which permits use, sharing, adaptation, distribution and reproduction in any medium or format, as long as you give appropriate credit to the original author(s) and the source, provide a link to the Creative Commons license, and indicate if changes were made. The images or other third party material in this article are included in the article's Creative Commons license, unless indicated otherwise in a credit line to the material. If material is not included in the article's Creative Commons license and your intended use is not permitted by statutory regulation or exceeds the permitted use, you will need to obtain permission directly from the copyright holder. To view a copy of this license, visit http://creativecommons.org/licenses/by/4.0/.
\end{abstract}

(C) The Author(s) 2019

\footnotetext{
${ }^{1}$ National "111" Center for Cellular Regulation and Molecular Pharmaceutics, Hubei University of Technology, Wuhan, Hubei 430068, China. ${ }^{2}$ Department of Physiology, Membrane Protein Disease Research Group, Faculty of Medicine and Dentistry, University of Alberta, Edmonton, AB T6G 2H7, Canada. ${ }^{3}$ Department of Biochemistry, University of Utah School of Medicine, Salt Lake City, UT 84112, USA. ${ }^{4}$ School of Life Sciences and Technology, Tongji University, Shanghai 200092, China. ${ }^{5}$ Experimentelle und Klinische Pharmakologie und Toxikologie, Universität des Saarlandes, Homburg 66421, Germany. ${ }^{6}$ Department of Biological Sciences, St. John's University, Queens, NY 11439, USA. 7 Keck Advanced Microscopy Laboratory and Department of Biochemistry and Biophysics, University of California, San Francisco, San Francisco, CA 94143, USA. These authors contributed equally: Wang Zheng, Xiaoyong Yang. Correspondence and requests for materials should be addressed to J.T. (email: jingfeng9930@163.com) or to E.C. (email: erhu.cao@biochem.utah.edu) or to X.-Z.C. (email: xzchen@ualberta.ca)
} 